\title{
Identification of a cis-Acting Regulatory Element Conferring Inducibility of the Atrial Natriuretic Factor Gene in Acute Pressure Overload
}

\author{
Rüdiger von Harsdorf, J John G. Edwards, ${ }^{\S}$ You-Tang Shen, ${ }^{\star}$ Raymond K. Kudej," Rainer Dietz," Leslie A. Leinwand, \\ Bernardo Nadal-Ginard, ${ }^{\star \ddagger}$ and Stephen F. Vatner* \\ *Department of Medicine, Harvard Medical School, Boston, Massachusetts 02115; Department of Medicine, Brigham and Women's \\ Hospital, Boston, Massachusetts 02115; and the New England Regional Primate Research Center, Southborough, Massachusetts 01772; \\ ${ }^{\ddagger}$ Department of Cardiology, Children’s Hospital, Boston, Massachusetts 02115; ${ }^{\S}$ Department of Microbiology and Immunology, Albert \\ Einstein College of Medicine, New York 10461; and ${ }^{\|}$Franz. Volhard Klinik und Max-Delbrück-Centrum, Humboldt Universität zu Berlin, \\ Berlin, Germany 13122
}

\begin{abstract}
To identify the cis-acting regulatory element(s) which control the induction of the atrial natriuretic factor (ANF) gene in acute pressure overload, DNA constructs consisting of promoter elements linked to a reporter gene were injected into the myocardium of dogs, which underwent aortic banding or were sham-operated. Expression of a reporter gene construct harboring the ANF promoter $(-3400 \mathrm{ANF})$ was induced 6-12-fold after $7 \mathrm{~d}$ of pressure overload. An internal deletion of $556 \mathrm{bp}$ (nucleotide sequence -693 to -137 ) completely abrogated the inducibility of the ANF reporter gene construct. An activator protein-1 (AP1)-like site (-496 to -489$)$ and a cAMP regulatory element (CRE) ( -602 to $-596)$ are located within the deleted sequence. Site-directed mutagenesis of the AP1-like site but not the CRE completely prevented the induction of this construct to acute pressure overload. Further, the AP1-like site was able to confer inducibility of a heterologous promoter $(\beta$-myosin heavy chain) to higher values than controls. Gel mobility shift assay (GMSA) supershift analysis was performed using a radiolabeled probe of the ANF promoter $(-506 /-483)$ that included the AP1-like site (ATGAATCA) sequence, as well as a probe converted to contain an AP1 consensus sequence (ATGACTCA). GMSA analysis demonstrated that the ANF AP1-like element could bind both a constitutively expressed factor and the AP1 proteins, and conversion to a true AP1 site increased its affinity for AP1. However, $7 \mathrm{~d}$ after the onset of pressure overload, the AP1 proteins were present only at low levels, and the major complex formed by the ANF AP1-like probe was not supershifted by a jun antibody. Using a large animal model of pressure overload, we have demonstrated that a unique cis-acting element was primarily responsible for the overload induction of the ANF gene. (J. Clin. Invest. 1997. 100:1294-1304.) Key words:
\end{abstract}

R. von Harsdorf and J.G. Edwards contributed equally to this work. Address correspondence to Dr. Stephen F. Vatner, Cardiovascular and Pulmonary Research Institute, Allegheny University of Health Sciences, 15th Floor, South Tower, 320 East North Avenue, Pittsburgh, PA 15212. Phone: 412-359-8255; FAX: 412-359-8257.

Received for publication 31 March 1996 and accepted in revised form 16 June 1997.

J. Clin. Invest.

(C) The American Society for Clinical Investigation, Inc. 0021-9738/97/09/1294/11 \$2.00

Volume 100, Number 5, September 1997, 1294-1304

http://www.jci.org cardiac hypertrophy $\bullet$ in vivo gene transfer $\bullet$ atrial natriuretic factor $\bullet$ promoter mapping $\bullet$ cis-acting regulatory elements

\section{Introduction}

Cardiac hypertrophy is the primary chronic compensatory mechanism to increased hemodynamic load, yet the underlying mechanisms leading to its development are poorly understood. It is likely that a better understanding will be derived from studies aimed at delineating molecular mechanisms involved in the initial responses to the inciting pressure or volume overload. The gene for atrial natriuretic factor $(\mathrm{ANF})^{1}$ has been studied extensively and is known to be induced in developing hypertrophy. During embryonic development, the ANF gene is expressed in both the atrium and the ventricle (1). Shortly after birth, the expression of ANF is downregulated in the ventricle, and the atrium is the primary site of ANF synthesis within the mature myocardium (2). Induction of ventricular hypertrophy is characterized by a reexpression of ANF in ventricular cells that represents the activation of an embryonic gene expression program in hypertrophied ventricular myocytes (3-6). The induction of ANF gene expression is a highly conserved feature of ventricular hypertrophy, and is found in a wide variety of species including mouse, rat, hamster, dog, and humans (5-10). It also occurs in response to various stimuli, including hormones, genetic propensity, hypertension, and pressure and volume overload $(3-6,10)$.

Attempts have been made to identify the cis-acting regulatory elements responsible for the hypertrophy-induced activation of immediate early and embryonic gene expression, including the ANF gene. Many studies aimed at dissecting the responses to hypertrophic stimuli have been restricted to transient transfection assays of cardiac cell cultures (11-19). It has been speculated that the transient activation of several protooncogenes that occurs in response to a hypertrophic stimulus may be involved in the activation of genes such as $\operatorname{ANF}(8,20)$. Molkentin and Markham, using an A-rich probe, demonstrated the upregulation of a transcription factor in ventricular extracts from rat hearts subjected to pressure overload for $11 \mathrm{~d}$ (21). Aoyagi and Izumo (22) demonstrated that stretch responsiveness of the c-fos gene was mediated by a serum re-

1. Abbreviations used in this paper: ANF, atrial natriuretic factor; AP1, activator protein-1; $\beta$ MHC, $\beta$-myosin heavy chain; CAT, chloramphenicol acetyltransferase; CRE, cAMP regulatory element; GMSA, gel mobility shift assay; LUC, luciferase; LV/BW, left ventricular/body weight; MSV, mouse sarcoma virus; PKC, protein kinase C; RSV, Rous sarcoma virus; SRE, serum response element. 
sponse element (SRE). This activation occurred via a protein kinase $\mathrm{C}$ (PKC)-dependent pathway, which is in agreement with previous studies elucidating the role of PKC in stretchinduced cardiac ANF release (11-13). Neither primary cardiomyocytes nor the isolated working heart preparation is suitable for examining the changes associated with continued increased hemodynamic overload. The consistent finding of pressure overload induction of ANF mRNA from undetectable levels in the ventricle suggests that transcriptional mechanisms may be of primary importance.

We have used the approach of DNA injection into the myocardium to identify a cis element within the ANF gene which responds to a pressure overload stimulus. A unique feature of this investigation is the use of a large mammal model of pressure overload. This is particularly important in light of the different biochemical and hemodynamic properties of the myocardium in large and small mammals. By injecting plasmid DNA directly into the myocardium (23-27) and initiating pressure overload by aortic banding, we addressed the following questions: ( $a$ ) Is ANF expression increased by pressure overload? (b) What is the cis-acting regulatory element conferring induction of the ANF gene in acute pressure overload? and (c) Is this putative cis-acting element able to confer inducibility on a heterologous promoter?

\section{Methods}

Materials. Restriction enzymes, T4 DNA ligase, and Vent DNA polymerase were obtained from New England Biolabs, Inc. (Beverly,
MA). Calf intestinal alkaline phosphatase was obtained from Boehringer Mannheim (Mannheim, Germany). ${ }^{14} \mathrm{C}$-chloramphenicol was obtained from New England Nuclear (Boston, MA). All other chemicals were purchased from Sigma Chemical Co. (St. Louis, MO).

Plasmids. MSV-CAT was created by fusing the coding sequence of the chloramphenicol acetyltransferase (CAT) gene (28) onto the long terminal repeat of the mouse sarcoma virus (MSV). Rous sarcoma virus (RSV)-luciferase was described previously (29). -256ApoAICAT was constructed by fusing the nucleotide sequence -256 to +500 of the $5^{\prime}$ flanking sequence of the rat apolipoprotein A-I (ApoAI) to the CAT gene (30). -667-3MHC-CAT contains the nucleotide sequence -667 to +34 of the rat $\beta$-myosin heavy chain (MHC) gene promoter fused to the CAT gene and inserted at the BamHI site of the polylinker of the pUC 18 plasmid. All other constructs used in this study are depicted in Fig. 1. -3400-ANF-CAT was a gift from Dr. Christine Seidman (Department of Human Genetics, Harvard Medical School, Boston, MA). It contains the 5' flanking sequence of the rat $\mathrm{ANF}$ gene ranging from nucleotide sequence -3400 to +61 inserted in the BamHI site of pO-CAT (31). Hind-ANF-CAT was constructed by deletion of a 556-bp HindIII fragment (nucleotide sequence -693 to -137 ) of the -3400 -ANF-CAT plasmid. $\triangle$ AP1ANF-CAT contains a sequence of the activator protein-1 (AP1)-like site of the ANF promoter (position -496 to -489), which was mutated from 5'-ATGAATCA-3' to 5'-AGGTACCT-3' (sequence of the sense strand), thus introducing a unique KpnI site. $\triangle \mathrm{CRE}$-ANFCAT was created by mutation of the cAMP regulatory element (CRE) of the ANF promoter (position -602 to -596) from 5'TGACTTCA-3' to $5^{\prime}$-TGGTACCG-3' (sequence of the sense strand), also introducing a KpnI site.

The heterologous promoter constructs were created by insertion of double-stranded synthetic oligonucleotides (Applied Biosystems, Inc., Foster City, CA) harboring the regulatory elements in tandem
A

-3400-ANF-CAT

$\triangle$ Hind-ANF-CAT

$\triangle$ AP1-ANF-CAT

$\triangle C R E-A N F-C A T$
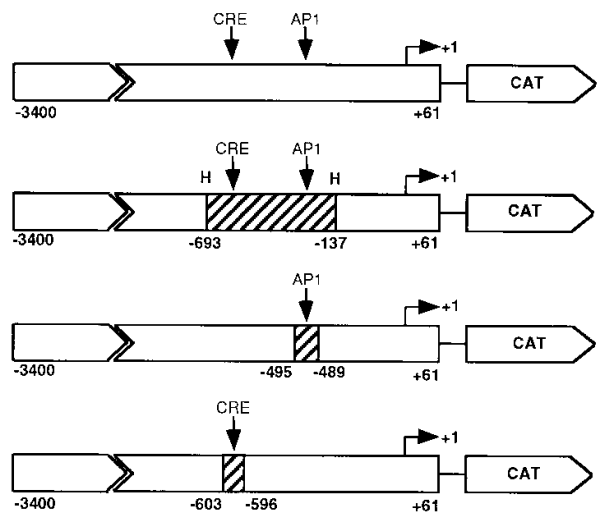

AP1-147-B-MHC-CAT

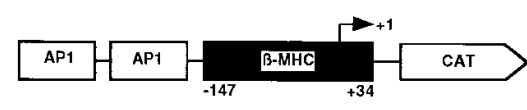

CRE-147-B-MHC-CAT

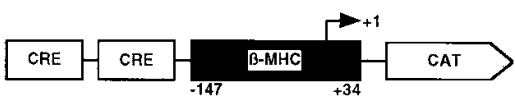

SRE-147-ß-MHC-CAT

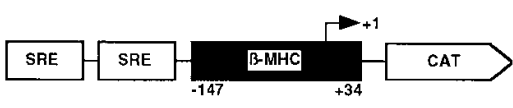

X/h-147-B-MHC-CAT

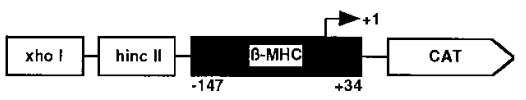

-147-ß-MHC-CAT

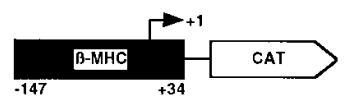

B

Sequence of the Wildtype and Mutated ANF-Promoter

-3400-ANF-CAT wt (-495 to -489)

$5^{\circ}-\ldots$ TGAATCA...-3'

$\triangle \mathrm{AP1}$-ANF-CAT (-495 to -489$)$

$5^{\prime}-\ldots$ GGTACCA ...-3'

-3400-ANF-CAT wt (-603 to -596)

$5^{\prime}-\ldots$ TGACTTCA $\ldots-3^{\prime}$

$\triangle$ CRE-ANF-CAT (-603 to -596)

$5 '$-..GGTACCCA ...-3

Sequence of the Inserts of the Heterologous Promoterconstructs

AP1-147-ß-MHC-CAT: 5'-TGAATCA (n=15) TGAATCA-3'

CRE-147-3-MHC-CAT: 5'-TGACTTCA (n=15) TGACTTCA-3'

SRE-147-B-MHC-CAT: $\quad 5^{\prime}$-CCATATTAGG $(n=15)$ CCATATTAGG-3'

$\mathrm{x} / \mathrm{h}$-147-ß-MHC-CAT: 5 -CTCGAG (n=15) GTCAAC-3'

Figure 1. (A) Schematic diagram of the wild-type (-3400-ANF-CAT), deleted ( $\triangle H$ Hind-ANF-CAT) and mutated $(\triangle A P 1-A N F-C A T$ and $\triangle C R E-A N F-C A T)$ ANF reporter gene constructs and the heterologous promoter constructs used for in vivo injection. $H$, HindIIIrestriction site. Hatched bars, deleted and mutated sequences. Black bars, $\beta$ MHC promoter sequences. The numbers indicated refer to the nucleotide position relative to the transcription start site. $(B)$ Actual sequences of the wild-type and mutated ANF promoter constructs (sense strand) at the indicated site of the ANF promoter introducing a unique KpnI site at the mutated regulatory element, and sequence of the heterologous promoter constructs (sense strand). $n=15$, a random sequence of 15 nucleotides ( $5^{\prime}$-TTAAATTTGAGAAAG-3') which separates the two regulatory elements. 
into a polylinker region upstream of the $\beta \mathrm{MHC}$ fragment of the -147-3MHC-CAT plasmid, which has the basal promoter of the rat $\beta M H C$ (sequence -147 to +34 ) fused to the CAT gene of the pOCAT plasmid. AP1-147- $\beta$ MHC-CAT contains the AP1-like sequence of the rat ANF promoter $5^{\prime}$-ATGAATCA-3' in tandem separated by 15 random nucleotides (the same random sequence $5^{\prime}$-TTAAATTTGAGAAAG-3' was used in all heterologous promoter constructs), cloned into the SphI site of the polylinker upstream of the

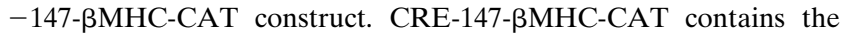
CRE sequence of the rat ANF promoter 5'-TGACTTCA-3' in tandem separated by 15 random nucleotides, cloned into the same site as the -147- $\beta$ MHC-CAT construct. SRE-147- $\beta$ MHC-CAT contains the SRE sequence from the mouse c-fos promoter $5^{\prime}$-CCATATTAGG-3' (32) in tandem separated by 15 random nucleotides, cloned into the SphI site of the $-147-\beta M H C-C A T$ construct. $x / h-147-\beta M H C-C A T$ contains an XhoI and a HincII restriction site separated by 15 random nucleotides, inserted into the SphI site of the $-147-\beta$ MHC-CAT construct.

Site-directed mutagenesis using PCR. Mutations of the relevant regulatory elements of the ANF promoter (AP1-like and CRE site, respectively) were created using PCR. The reaction template was the excised 556-bp HindIII fragment of the rat ANF promoter harboring both the AP1 and the CRE site. PCR was performed in a PerkinElmer Corp. GeneAmp 9600 apparatus (Norwalk, CT) for 25 cycles with the reaction conditions $94^{\circ} \mathrm{C}$ for $1 \mathrm{~min}, 55^{\circ} \mathrm{C}$ for $1 \mathrm{~min}$, and $65^{\circ} \mathrm{C}$ for $30 \mathrm{~s}$. The construction was performed in two PCR steps. First, the 5 ' flanking sequence adjacent to the AP1-like or CRE regulatory element was amplified using a forward primer with a flanking HindIII restriction sequence and a reverse primer with a flanking sequence of a KpnI restriction site. Second, the $3^{\prime}$ flanking sequence adjacent to the according regulatory element was amplified using a forward primer with a flanking KpnI restriction site and a reverse primer with a HindIII restriction site. After digestion of the PCR products with $\mathrm{KpnI}$, both products were ligated together to form a 556-bp fragment homologous to the excised 556-bp HindIII fragment, with the exception of a unique KpnI site at the according regulatory element. The ligation product was digested with HindIII and ligated back into the HindIII site of the ANF promoter. The correctness of the mutated sequence was verified by DNA sequencing.

Animal preparation, induction of pressure overload, and injection of plasmid DNA. In brief, dogs were premedicated with xylazine (10 $\mathrm{mg} / \mathrm{kg}$ intramuscularly), and general anesthesia was induced with thiamylal (10-20 mg/kg intravenously) and maintained with halothane $[0.5-1.5 \%$ (vol)]. Sterile technique was used, and the pericardium was exposed through a left thoracotomy at the fifth costal interspace. The pericardium was opened, and the heart was anchored with a suture through the apex. Up to $304-\mathrm{mm}^{2}$ patches of Dacron were sewn to the epicardium to mark injection sites. After placement of the patches, circular plasmid DNA resuspended in $1 \times$ PBS was injected through a 30-gauge needle inserted perpendicular to the epicardium (Fig. 2). The injection volume was $200 \mu \mathrm{l}$ each, and the concentration of DNA was $0.3 \mu \mathrm{g} / \mu \mathrm{l}$ for the CAT-reporter gene and $0.075 \mu \mathrm{g} / \mu \mathrm{l}$ for the luciferase-reporter gene. Constructs were injected at random labeled sites in order not to bias the potential for positional effects. Reporter gene constructs were always coinjected with a control construct (RSV-luciferase) to account for injection efficiency. After the injections, the incision was closed in layers, and the chest was evacuated (hereafter referred to as sham-operated group). In the pressure overload group, immediately after the gene injections, an aortic gradient was induced by placing a Teflon band around the ascending aorta which was gently tightened while the proximal and distal blood pressures were monitored via catheters connected to transducers (Statham Instruments, Hato Rey, PR). The left ventricular/aortic gradient in these dogs averaged $59 \pm 5.8 \mathrm{mmHg}$ at operation. All animals were observed during the recovery until fully conscious. The animals tolerated the surgical procedure well, and blood pressure, aortic gradient, and heart rate were determined daily. Animals used in this study were maintained in accordance with the guidelines of the Committee on Animals of the Harvard Medical School and the "Guide for the Care and Use of Laboratory Animals" (Department of Health and Human Services, National Institutes of Health publication 86-23).

Tissue preparation. After $7 \mathrm{~d}$ the animals were killed with an overdose of pentobarbital $(50 \mathrm{mg} / \mathrm{kg}$ intravenously), and the heart was rapidly excised and placed in ice-cold saline. The labeled injection sites were excised as transmural blocks of myocardium and immediately placed in liquid nitrogen. Tissue was stored at $-80^{\circ} \mathrm{C}$ until further processing. Immediately before the CAT assay, tissue was homogenized in $1 \mathrm{ml}$ homogenization buffer containing (mM) glycyl-

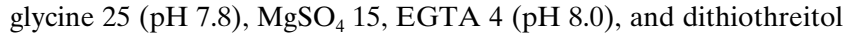
1 , as described previously (27). The suspension was centrifuged at $6,000 \mathrm{~g}$ for $15 \mathrm{~min}$ at $4^{\circ} \mathrm{C}$, and the supernatant was used for further analysis. The supernatant was normalized for protein content as determined by the Bradford assay (Bio-Rad Laboratories, Richmond, CA) by the appropriate dilution with homogenization buffer.

CAT assay. CAT assays were performed as described previously (33). Briefly, $10 \%$ of the supernatant, $1 \mu \mathrm{l}^{14} \mathrm{C}$-labeled chloramphenicol $(0.25 \mu \mathrm{Ci})$, and $5 \mu \mathrm{l} n$-butyryl coenzyme A $(5 \mathrm{mg} / \mathrm{ml})$ were mixed and filled to a total volume of $125 \mu \mathrm{l}$ with $250 \mathrm{mM}$ Tris- $\mathrm{HCl}, \mathrm{pH} 8.0$. The reaction mixture was incubated at $37^{\circ} \mathrm{C}$ for $2 \mathrm{~h}$, which was within the linear range of the reaction. The acetylated chloramphenicol fraction of the suspension was extracted by adding $300 \mu \mathrm{l}$ xylene. Suspensions were back-extracted twice with $250 \mathrm{mM}$ Tris-HCl, $\mathrm{pH}$ 8.0. Aliquots of $200 \mu \mathrm{l}$ were counted in scintillation fluid in a beta counter (model LS 6000IC; Beckman Instruments, Inc., Fullerton, CA). To



Figure 2. The technique for gene injection in the heart with aortic banding is shown. The left ventricular/aortic gradient in a chronically instrumented conscious dog $1 \mathrm{wk}$ after aortic banding is shown as an inset. The left ventricular and aortic pressure tracings are superimposed. Note the systolic left ventricular/aortic gradient of $\sim 90 \mathrm{mmHg}$. 
account for variation within the assay, background activity was assessed by running a reaction without addition of supernatant. Background activity was consistent throughout the study at 50-100 cpm.

Luciferase assay. Luciferase assays were performed as described elsewhere (27). In summary, $10 \%$ of the supernatant normalized for protein content was brought to a volume of $100 \mu \mathrm{l}$ with homogenization buffer (see Tissue preparation) and mixed with $360 \mu \mathrm{l}$ reaction buffer containing (mM) glycyl-glycine 25 ( $\mathrm{pH} 7.8), \mathrm{MgSO}_{4} 15$, EGTA 4 ( $\mathrm{pH} 8.0)$, dithiothreitol 1, $\mathrm{KPO}_{4} 15$ ( $\left.\mathrm{pH} 7.8\right)$, and ATP 2, along with $0.3 \%$ Triton X-100. Light emission was measured in a Monolight luminometer (LB 9501; EG\&G Berthold Inc., Wildbad, Germany) immediately after the addition of $0.2 \mathrm{mM}$ D-luciferin to the reaction mixture. Light units are expressed as the integral of activity measured over $20 \mathrm{~s}$. Only values within the linear range of the semilogarithmic dose response curve between the amount of luciferase and the emission of light were included for analysis.

Preparation of nuclear extracts. Eight dogs (four sham, four 7-d overload) were surgically prepared as described above. Nuclear extracts were prepared using a procedure modified from that described by Deryckere and Gannon (34). In brief, hearts were broken under liquid $\mathrm{N}_{2}$ or minced with fine scissors on ice in a low salt buffer $(150 \mathrm{mM}$ $\mathrm{NaCl}, 10 \mathrm{mM}$ Hepes, $\mathrm{pH}$ 7.9, $1.0 \mathrm{mM}$ EDTA, $0.5 \mathrm{mM}$ PMSF, $0.6 \%$ NP-40), dounced six strokes using a B pestle, and then centrifuged $\left(500 \mathrm{~g}, 30 \mathrm{~s}, 4^{\circ} \mathrm{C}\right)$ to remove debris. After this, nuclei were permitted to swell in solution on ice for $5 \mathrm{~min}$. The nuclei were then pelleted by centrifugation $\left(3,500 \mathrm{~g}, 5 \mathrm{~min}, 4^{\circ} \mathrm{C}\right)$ and lysed on ice for $20 \mathrm{~min}$ in a high salt solution $(420 \mathrm{mM} \mathrm{NaCl}, 20 \mathrm{mM}$ Hepes, $\mathrm{pH} 7.9,1.2 \mathrm{mM}$ $\mathrm{MgCl}_{2}, 0.2 \mathrm{mM}$ EDTA, $25 \%$ glycerol, $5 \mathrm{mM}$ dithiothreitol, $0.5 \mathrm{mM}$ PMSF, $2 \mathrm{mM}$ benzamidine, $0.5 \mu \mathrm{g} / \mathrm{ml}$ of pepstatin, leupeptin, and aprotinin). Insoluble debris was removed by a 15 -s spin in a microcentrifuge $(14,000 \mathrm{~g})$. Protein concentrations were determined using the Bio-Rad Laboratories Protein Assay, and aliquots were frozen at $-80^{\circ} \mathrm{C}$ until use.

Probes. The probes used for gel shift analysis were derived from the rat ANF 5' flanking region (-506/-483) (EMBL/GenBank/ DDBJ accession no. J03267), which included all of the DNase footprinted region reported using cardiac nuclear extracts (35). The probes used were made from single-stranded oligonucleotides and were made double-stranded by annealing and their ends filled in using the Klenow fragment before the double-stranded product was isolated from a $2 \%$ low melt agarose gel. Double-strand probes were end-labeled using $\mathrm{T}_{4}$ polynucleotide kinase. Wild-type ANF sequence is shown as uppercase letters below. The bold characters denote nucleotide changes within the Mut and AP1 conversion probes. The AP1 consensus probe was purchased from Santa Cruz Biotechnology (Santa Cruz, CA). The consensus strands were as follows: ANF probe: 5'-gatctACGAGGCCAATGAATCAGGTGTGActaga-3'; Mut probe: 5'-gatctACGAGGCCAAgGtAcCaGGTGTGActaga-3'; AP1 conversion probe: 5' -gatctACGAGGCCAATGAcTCAGGTGTGActaga-3'; and AP1 consensus: 5' -cgctggATGACTCAgccgaa-3'.

Gel mobility shift assay (GMSA). Extracts were thawed on ice before use. Assay conditions were adjusted to optimize binding for both the ANF probe and the AP1 consensus probe, and were based on the investigations of several reports focusing on AP1 binding (20, 35-39). The binding buffer used was $50 \mathrm{mM}$ Tris- $\mathrm{HCl}, \mathrm{pH} 7.9,2 \mathrm{mM}$ $\mathrm{MgCl}_{2}, 50 \mathrm{mM} \mathrm{KCl}, 5 \mathrm{mM}$ DTT, $0.5 \mathrm{mM}$ EDTA, and 5\% glycerol. The extracts were mixed with the binding buffer and $200 \mathrm{ng}$ of poly dIdC (Pharmacia Biotech, Piscataway, NJ) in a total volume of $20 \mu \mathrm{l}$ and incubated at room temperature for $10 \mathrm{~min}$. The radiolabeled probe was added, and the mixture incubated for $10 \mathrm{~min}$ at room temperature. $15 \mu \mathrm{l}$ of the mixture was then loaded on a $4 \%$ polyacrylamide $0.5 \times$ TBE gel. Gels were dried under vacuum and exposed to BioMax film (Eastman Kodak Inc., Rochester, NY). For the competition experiments, competitors were added just before the addition of labeled probe. For the supershift experiments, antibodies with epitopes specific to conserved regions of the jun (SC-44X; Santa Cruz Biotechnology) or fos (SC-47X; Santa Cruz Biotechnology) families were used. After the 10-min incubation with the labeled probe, $4 \mu \mathrm{g}$ antibody (or preimmune serum) was added to the appropriate tubes, and the mixture was incubated at $4^{\circ} \mathrm{C}$ for $4 \mathrm{~h}$ before being loaded onto the gel. Experiments in which the antibody had been peptideneutralized were performed by combining the c-jun antibody with the control peptide (SC-44P; Santa Cruz Biotechnology) overnight at $4^{\circ} \mathrm{C}$. This mixture was then used in the supershift assay.

Experimental design and data analysis. 10 adult mongrel dogs weighing 22-26 kg were used for the injection experiments. They were assigned to two groups with 5 dogs each, one group with aortic banding, one group as sham-operated animals. The injections were always done with a pair of dogs (banded/sham) and compared with one another. Each experiment included the injection of the full promoter ANF construct as a positive control. An $n$ refers to the number of injections per construct per dog. (All data are reported as mean \pm SEM.) Data are expressed as a CAT/luciferase (Luc) ratio to account for differences in injection efficiency. The variability between animals was $15 \%$ in both pressure overload-treated and sham animals based on the data from the longest ANF construct. If we assume that the other products would have similar variability between animals, then a twofold difference in the mean CAT/Luc ratio would be highly significant. Given that we must make this assumption, we considered more than a threefold difference significant. For the preparation of nuclear extracts, eight dogs were used (four sham, four 7-d overload). The hemodynamic data were derived from the banded dogs, and the two sham dogs were used for the nuclear extracts.

\section{Results}

Characterization of the pressure overload model. Dog hearts were injected with plasmid DNA, and the experimental group immediately subjected to an aortic gradient. Each dog received 20-28 separate injections into the left ventricle. $7 \mathrm{~d}$ after banding, the animals were killed, and each injection site was analyzed for expression of the injected gene. Serial hemodynamic monitoring confirmed the maintenance of the left ventricular/aortic gradient, which was $98 \pm 5.2 \mathrm{mmHg}$ after $1 \mathrm{wk}$ (Table I). An example of the left ventricular/aortic gradient is shown in Fig. 2. Consistent with this model, despite the maintenance of a significant left ventricular/aortic gradient for $1 \mathrm{wk}$, there was no evidence of gross left ventricle hypertrophy or increase in the left ventricular/body weight $(\mathrm{LV} / \mathrm{BW})$ ratio. This is consistent with the investigation of a regulatory process which would induce cardiac hypertrophy rather than being the consequence of it.

Table I. Hemodynamics and Morphology

\begin{tabular}{|c|c|c|c|c|}
\hline & Sham & & Presure overload & \\
\hline & & $n$ & & $n$ \\
\hline \multicolumn{5}{|l|}{ Left ventricular } \\
\hline systolic pressure (mmHg) & 125 & 2 & $214 \pm 5.9$ & 7 \\
\hline Aortic systolic pressure $(\mathrm{mmHg})$ & 123 & 2 & $116 \pm 6.1$ & 7 \\
\hline Mean aortic pressure $(\mathrm{mmHg})$ & 103 & 2 & $96 \pm 4.9$ & 7 \\
\hline \multicolumn{5}{|l|}{ Left ventricular/ } \\
\hline aortic gradient $(\mathrm{mmHg})$ & 2 & 2 & $98 \pm 5.2$ & 7 \\
\hline Body weight (kg) & $23.7 \pm 1.1$ & 5 & $24.3 \pm 0.6$ & 5 \\
\hline Left ventricular weight $(\mathrm{g})$ & $115.4 \pm 12.4$ & 5 & $123 \pm 10.3$ & 5 \\
\hline \multicolumn{5}{|l|}{ Left ventricular weight/ } \\
\hline body weight (g/kg) & $4.89 \pm 0.52$ & 5 & $5.10 \pm 0.50$ & 5 \\
\hline
\end{tabular}


Table II.

Sham

Pressure overload

CAT/Luc $\times 100$

$\begin{array}{lcc}\text { MSV-CAT } & 1936 \pm 58 & 1705 \pm 123 \\ \text { ApoA1-CAT } & 8 \pm 1 & 10 \pm 1 \\ -3400-A N F-C A T & 40 \pm 3 & 235 \pm 6^{*} \\ -667-\beta-M H C-C A T & 290 \pm 17 & 345 \pm 8\end{array}$

*Significantly different.

Injected ANF reporter gene constructs are transactivated in canine cardiac ventricle in developing cardiac hypertrophy. Constitutive viral promoters derived from MSV or RSV linked to reporter genes (MSV-CAT, RSV-LUC) were expressed at high levels in both normal and banded myocardium (Table II). Their expression level (CAT/Luc ratio) was unchanged by pressure overload. RSV-LUC was coinjected with all mammalian promoter CAT constructs as an internal control. Used as a negative control, the -256 ApoAI-CAT construct contains the promoter of the hepatocyte-specific ApoAI gene and was expressed at levels close to background activity, reflecting the cell specificity of expression. The $-667-\beta M H C-C A T$ construct was expressed at high levels in both the sham-operated and banded groups. The ANF promoter construct (-3400-ANFCAT) was expressed at very low levels in the normal cardiac ventricle. However, in the group subjected to aortic banding, there was a sixfold increase in expression of the injected ANF construct (Fig. $3 A$ ).

Induction of the ANF gene is conferred by a regulatory element located within a 556-bp region of the ANF promoter. In transient transfection assays of cultured neonatal rat cardiac cells, a 556-bp fragment of the rat ANF gene promoter was shown to be necessary for basal ANF expression (20). This fragment was also shown to be necessary for inducible expression in pressure overload, since a construct harboring a deletion of the same $556 \mathrm{bp}$ of the $5^{\prime}$ flanking region of the ANF gene $(\Delta$ Hind-ANF) did not increase reporter expression in re- sponse to banding (Fig. $3 A$ ). As in cell culture studies, there was also a $40 \%$ reduction in basal activity of this construct in the sham-operated animal. Because removal of this region abrogated pressure overload responsiveness, we did not perform an extended deletion analysis of the ANF 5' regulatory region. This finding may indicate the presence of an unidentified element(s) within this region involved in both basal and inducible transcription of the ANF gene.

The ANF AP1-like site is essential for pressure overload induction of the ANF gene. The 556-bp fragment implicated in pressure overload responsiveness contains two DNA sequences which are candidate elements for conferring indelibility of the ANF gene. There is an AP1-like site (ATGAATCA: -496 to -489) and a CRE (TGACTTCA: -602 to -596). We defined this sequence as AP1-like because it differs by a single basepair change from the AP1 consensus sequence of 5'-ATGACTCA-3'. We modified each of these sites within the ANF promoter by site-directed mutagenesis. As depicted in Fig. $3 B$, neither mutation alone had a significant effect on the basal expression of the ANF reporter gene construct. However, after $7 \mathrm{~d}$ of banding, while the CRE-mutated construct was induced 11-fold, the construct mutated in the AP1-like site was not induced. The mutation in the AP1-like site within the context of the -3400ANF construct completely prevented the inducibility of the ANF gene in response to $7 \mathrm{~d}$ of pressure overload. These results indicate that the ANF AP1-like site is necessary to confer pressure overload responsiveness on the ANF reporter.

To test the hypothesis that the AP1-like site is sufficient for inducibility of the ANF gene in cardiac hypertrophy, we constructed heterologous promoter constructs using a basal promoter fragment of the $\beta \mathrm{MHC}$ gene, which was long enough to confer cardiocyte-specific expression but was not induced by pressure overload (147- $\beta$ MHC-CAT). As depicted in Fig. 4 A, hypertrophic induction can be conferred on the $\beta M H C$ gene basal promoter by the AP1-like site (compared to -147$\beta M H C-C A T)$ but not by the CRE site. Since the AP1-like sequence is palindromic, we did not account for orientationdependent expression of the AP1-like site. It is noteworthy that the AP1-147- $\beta$ MHC-CAT construct was also induced sig-
A

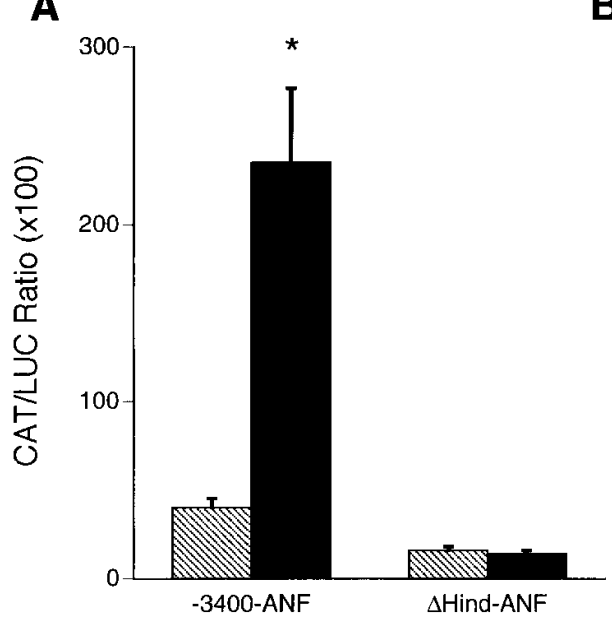

B

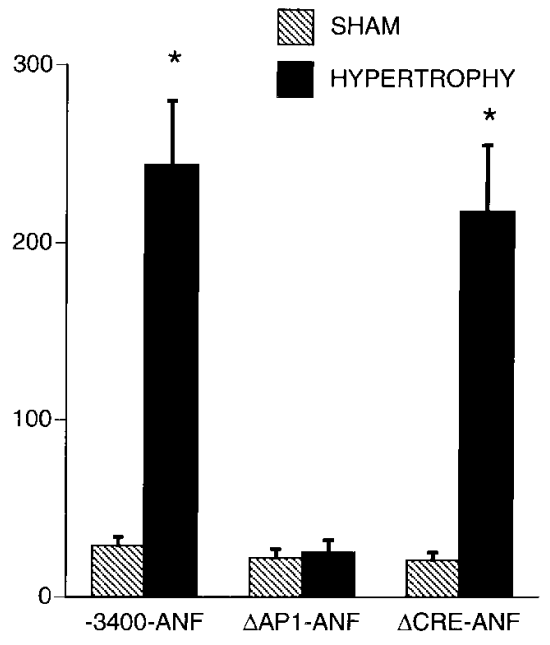

Figure 3. Influence of pressure overload on the expression of ANF reporter constructs. $(A)$ CAT reporter gene constructs driven by the wild-type ANF promoter $(-3400-A N F)$ or by the ANF promoter with a deletion of a 556-bp HindIII fragment $(\triangle H i n d-A N F)$. (B) Influence of sitedirected mutation on ANF reporter expression in response to overload. CAT reporter gene constructs driven by the wild-type ANF promoter ( $-3400-A N F)$, the ANF promoter containing a mutated AP1 site $(\triangle A P 1-A N F)$, or by the ANF promoter containing a mutated CRE $(\triangle C R E$ $A N F$ ). CAT values were corrected for the corresponding luciferase value at the same injection site $(\mathrm{CAT} / \mathrm{LUC}$ ratio $\times 100)$. Pressure overload group (black bars), shamoperated group (hatched bars). Values are mean $\pm \operatorname{SEM}(n=10$ for each construct).

*Significantly different compared to sham. 
A

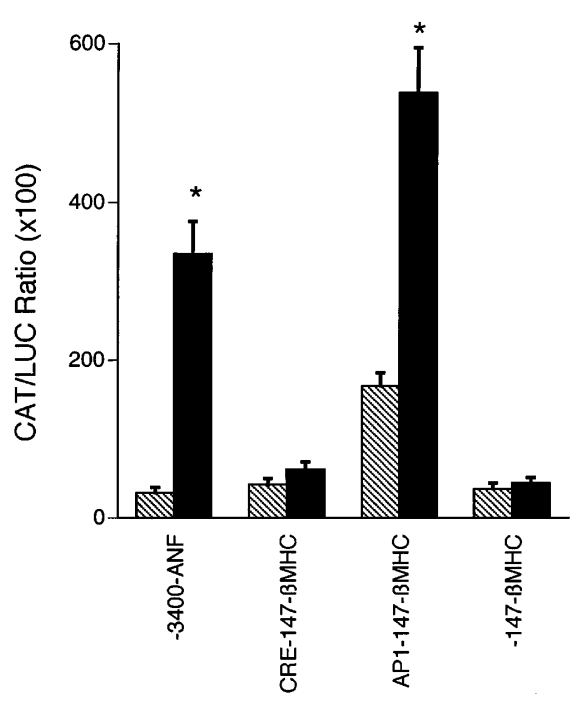

B

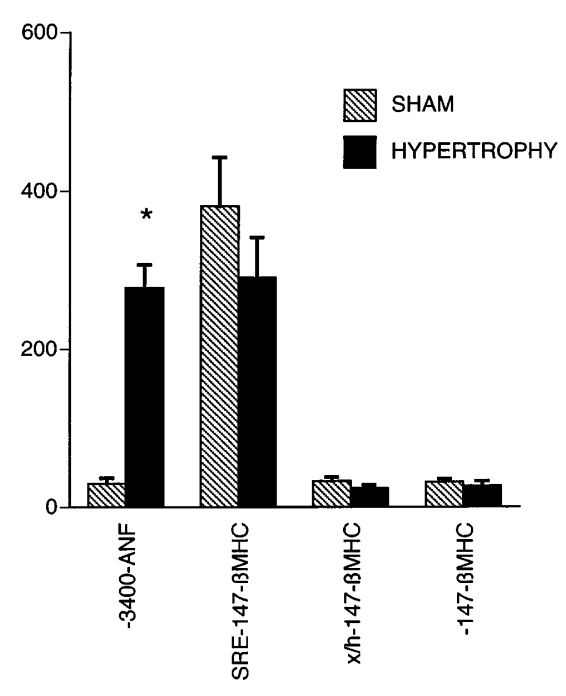

Figure 4. Influence of pressure overload on the expression of heterologous reporter constructs. $(A)$ Different regulatory cis-acting elements (AP1 site: AP1-147$\beta M H C$; CRE: $C R E-147-\beta M H C)$ were fused to the basal promoter sequence of the $\beta M H C$ gene $(-147-\beta M H C)$. Wild-type ANF promoter, $-3400-A N F$. (B) Different regulatory cis-acting elements (SRE: $S R E$ 147- $\beta M H C ; \mathrm{x} / \mathrm{h}-147-\beta M H C$ : random oligonucleotide sequence) were fused to the basal promoter sequence of the $\beta \mathrm{MHC}$ gene (-147- $\beta$ MHC). CAT values were corrected for the corresponding luciferase value at the same injection site (CAT/LUC ratio $\times 100)$. Pressure overload group (black bars), sham-operated group (hatched bars). Values are mean \pm SEM ( $n=7$ for each construct). *Significantly different compared to sham. nificantly in the sham-operated dog, indicating an activation through the AP1-like site independent of the pressure overload stimulus. This may reflect some interaction between the AP1-like site and $\beta \mathrm{MHC}$ sequence, facilitating basal transcription. However, pressure overload significantly increased the expression of this construct.

To exclude any nonspecific activation of heterologous promoter constructs, we also injected a construct with a random oligonucleotide sequence cloned $5^{\prime}$ to the $\beta \mathrm{MHC}$ basal promoter (x/h-147- $\beta$ MHC-CAT). Neither this construct nor the $147-\beta M H C-C A T$ was expressed at high levels in either animal (Fig. $4 B$ ).

The ANF promoter sequence of the rat also contains a serum response element (SRE or CArG-box) within the deleted 556-bp sequence $(-423$ to -399$)$. As depicted in Fig. $4 \mathrm{~B}$, the heterologous $\beta \mathrm{MHC}$ promoter construct harboring an SRE was expressed at high levels in the sham-operated dog and was not induced by pressure overload, suggesting that the SRE may be important for basal but not inducible transcription of the ANF gene.

The ANF AP1 site is recognized by DNA-binding proteins. Given the apparent role of an AP1-like site in pressure overload responsiveness, it was important to determine whether the well-characterized AP1 activity was mediating this response. Experiments were performed to optimize DNA-protein interactions for both the rat ANF AP1-like and the AP1 consensus elements $(20,35-40)$. Nuclear extracts from the hearts of control or overload dog ventricles were incubated with the ANF AP1-like sequence, and a single major complex resulted (Fig. 5). Laser densitometric scan indicated that binding was not altered significantly between control and banded animals. Therefore, $7 \mathrm{~d}$ of pressure overload did not produce an apparent qualitative or quantitative shift in the trans-acting factors that bound to the ANF AP1-like site. To determine specificity of binding activity of the ANF cis element, a GMSA competition analysis was performed. A labeled ANF AP1-like double-strand probe was incubated with $(a)$ unlabeled ANF AP1-like double-strand DNA (self) (Fig. 6, lanes 2-4), (b) unlabeled ANF/MUT double-strand DNA (Fig. 6, lanes 5-7), (c) unlabeled ANF to AP1 conversion double-strand DNA (Fig. 6 , lanes $8-10)$. The molar range of unlabeled competitors used was from 10- to 100-fold, comparable to other studies that examined AP1 binding (14, 20,35-44). The unlabeled ANF probe DNA (self) was able to compete effectively, indicating that DNA-protein complex was the result of a specific interaction (Fig. 6). The MUT competitor, which contained the same base-pair conversions used in the $\triangle \mathrm{AP} 1-\mathrm{ANF}$ reporter, did not compete well, and only at the highest concentration used were there any indications of altered binding. The AP1 conversion probe was able to compete effectively. However, comparison of binding at the $\times 50$ concentration (Fig. 6) suggests that the AP1 conversion DNA was not as competitive as the self DNA. The data clearly indicate that the complex formed was the result of a sequence-specific DNA-protein interaction.



Figure 5. GMSA supershift analysis using canine ventricle nuclear extracts prepared from sham (lanes 1-4) or 7-d pressure overload (lanes 5-8) dogs. Lane 9 represents probe incubated without extract. $10-\mu \mathrm{g}$ extracts were incubated in binding buffer for $10 \mathrm{~min}$ at room temperature before the ${ }^{32} \mathrm{P}-\mathrm{ANF}$ AP1 double-stranded oligonucleotide was added for an additional $10 \mathrm{~min}$. In the presence of ventricular nuclear extracts, the labeled DNA formed a single complex. 


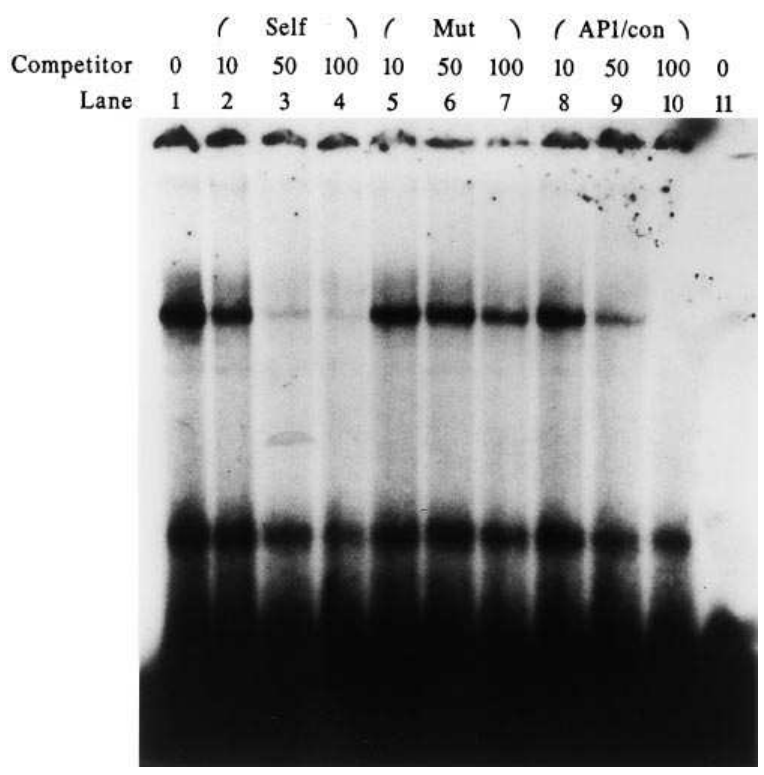

Figure 6. Competition GMSA analysis of canine ventricle nuclear extracts. $10 \mu \mathrm{g}$ nuclear extracts was incubated in binding buffer for 10 min before the competitors were added, immediately before the ${ }^{32} \mathrm{P}$ ANF double-stranded oligonucleotide. Competition analysis using cold competitors including self (ANF/AP1) (lanes 2-4), ANF/Mut (lanes 5-7), and AP1 conversion (lanes 8-10) is indicated as molar ratio (10-100) of labeled probe at the top of the panel. Lane 1 contains no competitor, and lane 11 contains no extract. The ANF/Mut oligonucleotide contains the same nucleotide substitutions used for construction of the AP1-ANF-CAT reporter construct. The labeled oligonucleotide formed a single complex that was specifically competed by the unlabeled self DNA and by the AP1/con DNA.

Rosenzweig et al., using recombinant fos and jun, demonstrated that the AP1 proteins bound to this region of the rat ANF gene (20). Given the sequence conservation with the AP1 consensus, this may not be surprising. To determine further whether the proteins binding to the ANF AP1-like site are related to the components of AP1 activity, a supershift assay was used. Antibodies recognizing conserved region epitopes of either the fos family (c-fos, fos $\mathrm{B}, f r a-1, f r a-2)$ or jun family (c-jun, jun B, jun D) were used. As a control, a commercially available double-strand AP1 consensus probe (Santa Cruz Biotechnology) containing only the core septamer of the AP1 consensus sequence was used to determine antibody specificity. Experiments using canine ventricle extracts from a dog subjected to pressure overload, and using preimmune serum, or in which the jun antibody was peptide-neutralized, indicated that the antibody-induced supershift was the result of a specific interaction (Fig. $7 A$ ). Similar results were obtained using extracts prepared from COS cells induced with a phorbol ester for $30 \mathrm{~min}$ (data not shown). None of the probes used formed a supershifted band in the presence of the preimmune serum. Although the ANF and the AP1 conversion probes were identical except for a single base-pair substitution, their binding patterns were somewhat different. The ANF probe formed a single complex, and there was no indication that it was supershifted by the jun antibody (Fig. 7 B). The short ANF consensus probe formed a single complex of a different mobility than that formed by the ANF probe. The short AP1 consensus probe was supershifted in the presence of the jun antibody. The ANF to AP1 conversion probe formed a doublet that had mobilities that appeared to coincide with the other two probes, and a supershifted band was observed in the presence of the jun antibody, suggesting that the upper band was influenced by the antibody. Using extracts prepared from COS cells stimulated with a phorbor ester, it was observed that the ANF probe formed a doublet (data not shown). These data indicate that under the proper conditions, the ANF element will form two separate complexes, one of which contains the AP1 proteins. This suggests that this element is capable of interacting in vitro with both inducible and constitutively expressed proteins.

\section{Discussion}

We have demonstrated the feasibility of gene injection into canine myocardium for studying gene regulation under physiological and pathological conditions. In this study, the model was acute pressure overload for a 7-d period. Although the pressure gradient placed upon the animals did not cause a significant increase in the $\mathrm{LV} / \mathrm{BW}$ ratio after $7 \mathrm{~d}$, this protocol has been shown to produce a $25 \%$ increase in the $\mathrm{LV} / \mathrm{BW}$ ratio after $6 \mathrm{wk}$ of pressure overload (45). $3.4 \mathrm{~kb}$ of sequence upstream of the ANF promoter responded by a 6-12-fold induction after $7 \mathrm{~d}$ of pressure overload, compared to sham-operated animals. Deletion analysis of the ANF promoter revealed a 556-bp fragment to be necessary for this response. Furthermore, we provide evidence that the responsible cis-acting regulatory element located within this 556-bp fragment is an AP1-like site. The ANF AP1-like element binds a constitutively expressed factor, whose apparent concentration is uninfluenced by $7 \mathrm{~d}$ of pressure overload, as well as the AP1 proteins. The ANF AP1like site is essential to confer overload inducibility on the ANF gene.

The molecular and biochemical mechanisms of cardiac hypertrophy have been the subject of numerous studies. Several different stimuli have been implicated, including stretch, adrenergic agonists, peptide growth factors, and cyclic nucleotides. Although myocardial adaptation occurs at several levels, transcriptional regulation provides a mechanism for integrating several different stimuli. For example, Kariya et al. have shown that for the $\beta \mathrm{MHC}$ gene, adrenergic stimulation of the gene is mediated through $\beta \mathrm{PKC}$, possibly by modulating the phosphorylation state of TEF-1 $(18,19)$. Similarly, C/EBP, a CCAAT/enhancer binding protein also found in the heart, may also be modified by PKC (20). The possibility of multiple ciselements acting in collaboration has been suggested by Sprenkle et al., who demonstrated the requirement of multiple SRE to fully transduce $\alpha$-adrenergic stimulation within the ANF gene (39).

Characteristic of the pressure overload response is a strong transient increase in expression of the immediate early genes and a prolonged increase in ventricular ANF synthesis as well as of several other structural proteins normally expressed in the fetal heart (8). Among the immediate early genes are c-fos and c-jun, whose pressure overload responsive element appears to be the SRE acting via a PKC-dependent pathway (35). Rosenzweig et al. speculated that, since members of the immediate early family such as fos and jun bind to AP1 elements of numerous genes, an initial stimulation of ANF expression by fos or jun would be reasonable to hypothesize (20). However, the influence of fos and jun on ANF expression re- 
A

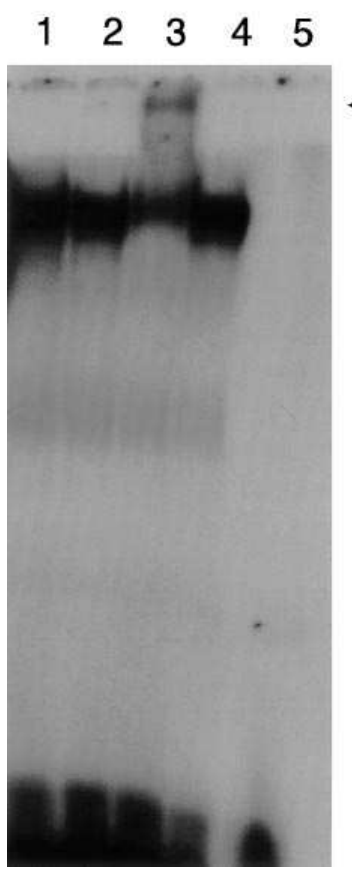

B
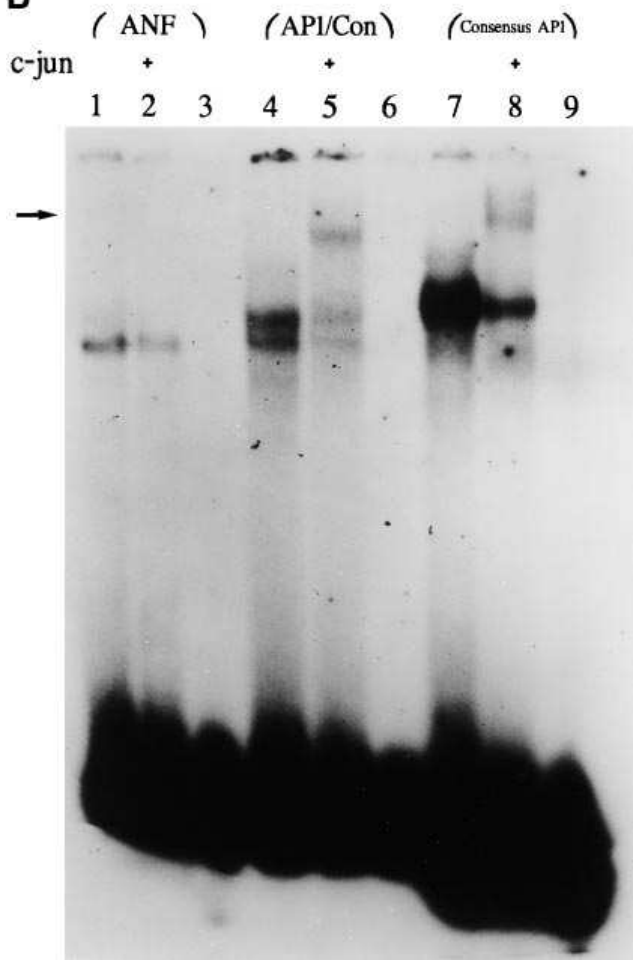

Figure 7. (A) Antibody specificity using canine ventricle extracts. The ${ }^{32} \mathrm{P}-\mathrm{AP} 1$ consensus double-strand probe was incubated with canine ventricle extract in the presence or absence of the c-jun antibody. Lane 1 , no antibody; lane 2, preimmune serum; lane 3, c-jun antibody; lane 4, peptide-neutralized c-jun antibody; lane 5, contains no extract. (B) GMSA supershift analysis using canine ventricle extracts and either ${ }^{32} \mathrm{P}$-ANF/AP1, ${ }^{32} \mathrm{P}$-AP1/Con(version), or consensus ${ }^{32} \mathrm{P}$-AP1 double-strand probes. ${ }^{+}$Presence of the c-jun antibody. Arrow, Position of the supershifted complex. Lanes 3, 6, and 9 contain no extract. The AP1/Con probe is identical to the ANF probe except for a single $\mathrm{A} \rightarrow \mathrm{C}$ conversion. The consensus AP1 probe was obtained from Santa Cruz Biotechnology and contains the core septamer of the AP1 binding site. Both the AP1/Con and the consensus AP1 labeled probes formed complexes that were supershifted by the jun antibody, whereas the ANF probe did not. mains unclear. Kovacic-Milivojevic and Gardner found that cotransfection of fos or jun expression constructs into rat neonatal cardiocytes could either stimulate or inhibit expression of a human ANF reporter, in a dose-dependent fashion (40). McBride et al. (14), using a similar experimental paradigm, demonstrated that overexpression of c-fos and c-jun could repress transcriptional activity of a transfected rat ANF promoter. However, these experiments were carried out in disassociated neonatal cardiac myocytes, and therefore the results might not apply to the intact adult heart.

We chose to use the rat ANF promoter since its 5' flanking sequence has been well-characterized in both transfection and transgenic studies $(7,14,20,31,35,39,46)$. Several different functional cis elements have been demonstrated including multiple SRE that appear important for transducing the $\alpha$-adrenergic response $(39,46)$. The SREs also appear important for maintaining basal expression in neonatal cardiomyocytes. Sprenkle et al. demonstrated that mutagenesis of the SRE, located at -114 , reduced basal expression (39). The SRE confers inducibility to the c-fos promoter upon growth stimulation of cardiac myocytes as well as in the response of the c-fos gene to stretch in an isolated perfused heart model $(22,47)$. Thus, SRE seems to play an important role in the early hypertrophic process for activation of some immediate early genes, including c-fos (20). In this study, the injection data of the SRE-147$\beta \mathrm{MHC}$ construct are in agreement with the work of Argentin et al. (35), suggesting a role for the SRE in the basal transcription of the ANF gene, since a marked induction of the SRE$147-\beta \mathrm{MHC}$ construct was observed in the sham-operated group (Fig. $4 \mathrm{~B}$ ) that was not further increased by banding. Although we did not specifically mutate the SRE within the context of the wild-type ANF promoter, the expression data of the heterologous promoter constructs would seem to rule out involve- ment of the SRE as a mediator of ANF induction after $7 \mathrm{~d}$ of overload. We cannot dismiss the possibility that the SRE may have a transient role in ANF induction. However, establishing its role may be difficult, since, as Sprenkle et al. demonstrated, with the ANF gene, multiple SREs are involved in the response to $\alpha$-adrenergic agonists (39).

We focused our attention on the CRE site, since it is known to be involved in the transduction of a variety of growth stimulatory processes $(41,44,48)$. The CRE binds CREB, and has been shown to confer inducibility on a variety of genes involved in growth processes (see reference 48 for a review). Additionally, it may be a regulatory element of the ANF promoter involved in $\beta$-adrenergic-induced hypertrophy in neonatal rat cardiocytes (46). Site-directed mutagenesis of the CRE within the ANF promoter did not affect either basal or inducible expression. The increase in cAMP content in hypertrophic myocardium does not seem to be crucial for the induction of the hypertrophic cardiac phenotype (46-49). However, the activation of the PKC pathway appears to be involved in the hypertrophic expression pattern $(20,21)$. Thus, the lack of a requirement for the CRE for ANF gene induction in developing cardiac hypertrophy in our experiments provides additional evidence for the hypothesis that cAMP does not play a crucial role in pressure overload induction of ANF expression.

In response to banding, expression of the ANF reporter was increased 6-12-fold. The ANF AP1-like sequence, when linked to a heterologous promoter, demonstrated that this sequence was sufficient to confer pressure overload responsiveness. Direct comparisons between heterologous and wild-type reporter constructs are difficult. For example, the basal activity of the 2XAP1 construct was fivefold greater than that of the wild-type ANF promoter (-3400ANF) or $\beta$ MHC minimal promoter (2X147) in the sham animal. Pressure overload in- 
creased the activity of the 2XAP1 construct in the context of the heterologous promoter only threefold over sham values, but this was 12 -fold above that of the $\beta M H C$ minimal promoter (2X147). The data suggest that the ANF AP1-like element was sufficient to confer overload responsiveness on the ANF gene. Site-specific mutation of the ANF AP1-like element abrogated the response to pressure overload, indicating that the site was accessible within the context of the longest ANF reporter construct $(-3400 \mathrm{ANF})$. More importantly, it indicates that the site is necessary to confer pressure overload responsiveness on the ANF gene. The experiments do not rule out potential cooperativity with other response elements or the possibility that other elements may have a temporal importance. Collectively, these data indicate that the ANF AP1-like element is responsible for conferring pressure overload responsiveness on the ANF gene.

Our results are different from those of Knowlton et al., who studied the effects of banding in both transgenic mice bearing an ANF reporter gene and mice injected with rat ANF reporter constructs (7). These investigators did not observe an increase in reporter expression after $7 \mathrm{~d}$ of banding. In response to $7 \mathrm{~d}$ of pressure overload, we did observe a consistent increase in ANF reporter gene expression in a canine model of pressure overload. Several factors may account for the divergent results. There are important species differences in the biochemical characteristics of the myocardium, including differences in the predominant MHC isoform present, which may create different strategies for myocardial adaptation to overload. After $7 \mathrm{~d}$ of banding, Knowlton et al. (7) observed a $27 \%$ increase in the LV/BW ratio, whereas we did not find a significant increase $(4 \%)$ at that time point. The pressure gradient used in this study of canines has been shown to induce hypertrophy of $\sim 25 \%$ (LV/BW) after 6 wk of banding (45). This suggests that the time course of adaptation may be distinct, and this may have influenced the intracellular response. There may also be some methodological differences. The ratio of ANF reporter to the reporter used to normalize for transfection efficiency was higher in our study. This may have potentiated the response. The variability of our canine data was smaller than that presented by Knowlton et al. (7). Although the reason for this is unclear, it may relate to the difficulty in performing plasmid injections into the free wall of a small mouse heart. Using in situ hybridization of pressure-overloaded rat hearts, Schiaffino et al. demonstrated regional and nonsynchronous expression of hypertrophic markers (50). This suggests that differences in wall stress may have an effect on ANF expression. Injection into the apex where wall stress is less likely to be altered by hypertrophy may partially account for the inability to detect significant changes in reporter expression. Because of the size and similarity of canine and human myocardium, it may be possible to investigate regional differences in the expression patterns of the canine myocardium using some of these hypertrophic markers.

Our competition experiments using the double-strand unlabeled ANF and AP1 conversion oligonucleotides found that both were able to displace binding of the ANF probe. Other competition experiments using a probe containing only the core septamer of the ANF sequence (ATGAATCA) found that only the higher concentrations of the AP1 consensus probe could compete for binding (data not shown). The Mut DNA could not effectively displace binding, indicating that even minor changes in the core septamer of the site strongly affected the in vitro DNA-protein interaction. Single nucleotide changes in the AP1 consensus sequence have previously been shown to decrease affinity for the AP1 proteins $(36,37$, 51). Busch and Sassone-Corsi, using the same sequence as the rat ANF element (TGAATCA), also found a different binding pattern compared to the AP1 consensus sequence (51). Nakabeppu et al. demonstrated that DNA unlabeled competitors containing the core septamer TGACTCT or TGACTCG were unable to compete for binding with the AP1 consensus sequence (TGACTCA), even when presented at a 400-fold excess (37). Collectively, the data indicate that the DNA-protein interaction is sequence specific and also suggest that the DNA-protein interaction is essential for the pressure overload-induced increases in ANF reporter expression.

The results of the DNA-protein binding experiments are consistent with previously published reports $(14,20,40)$. Kovacic-Milivojevic and Gardner (40) demonstrated that in vitro translated fos and jun bound to a human ANF KpnI/PvuII fragment located $-337 /-208$, a region different from the region we have studied. Rosenzweig et al. (20), using recombinantly produced fos and jun, demonstrated that the AP1 proteins bound to the same ANF region $(-506 /-483)$ in the rat ANF gene as we have studied. In the presence of purified fos/ jun, they demonstrated that an unlabeled AP1 consensus element could compete as effectively for AP1 binding as an unlabeled self competitor. They obtained a somewhat different result using atrial nuclear extracts. Using a fragment containing the ANF AP1-like region, they demonstrated that an unlabeled self competitor could effectively displace the DNA-protein complex, but that an unlabeled AP1 consensus element competed only poorly. This suggests that two different complexes may have been formed. These findings are replicated in our study. We found, using canine extracts, that the ANF probe formed a single complex with a constitutively expressed factor. Using phorbol ester-stimulated COS nuclear extracts, the ANF probe could form a doublet, suggesting that the cis element was capable of binding more than one set of proteins. Conversion of the ANF sequence to a true AP1 consensus sequence resulted in the formation of a doublet which could be supershifted by the jun antibody, suggesting that the conversion increased AP1 binding affinity, and that in the presence of sufficient quantities of the AP1 proteins, the wild-type ANF site will bind the AP1 proteins. Collectively, these data indicate that the ANF AP1-like element is capable of binding both the AP1 proteins and a yet unknown constitutively expressed factor.

Our in vivo transfection experiments demonstrate that the rat ANF AP1-like site transduces the overload stimulus after $7 \mathrm{~d}$ of banding. It is possible that other cis elements may contribute to this response; however, it is clear that within the time frame of these experiments, the AP1-like site is the critical element. Argentin et al. (35), using cardiomyocyte extracts, performed a DNase footprint analysis and demonstrated that the AP1-like site lies within a 22-bp protected region. Our experiments using heterologous promoters or site-directed mutagenesis of the longest ANF reporter clearly indicated that the ATGAATCA sequence was the critical site within this region. When the 22-bp region was submitted to a sequence similarity analysis using NCBI Blast software, matching sequence was found only for the rat ANF gene. This is a somewhat surprising finding, since pressure overload has been shown to increase the expression of several gene products. The ANF AP1-like 
region is not replicated in the $5^{\prime}$ flanking region of the related natriuretic peptide, BNP. This is not an altogether surprising finding, since the response of the two gene products to stretch is somewhat different. Aoyagi and Izumo (22) and Mantymaa et al. (52) have used isolated perfused rat hearts to examine the early response to $2 \mathrm{~h}$ of stretch in rat hearts. They observed increases in c-fos and BNP expression, but ANF expression was unresponsive to this short duration of stretch. Neither of those studies identified a functional pressure overload response element or demonstrated which signaling pathway might be responsible for pressure overload induction of ANF expression. This suggests that the response to pressure overload may be mediated by a complex set of signaling pathways that may have a temporal dependency.

Our studies demonstrate that $7 \mathrm{~d}$ of pressure overload increase ANF reporter expression, and that a single ANF AP1like site is primarily responsible for this increase. This element was functional not only in the -3400ANF-CAT construct, but also when linked to a heterologous promoter. Further, sitespecific mutation of the element in the context of a much longer construct abolished its responsiveness to pressure overload, indicating that it is accessible within the ANF promoter. Both observations are important for establishing that this element is necessary and sufficient for increasing ANF reporter expression in response to pressure overload. We show that the ANF AP1-like element is recognized by two distinct proteins, one of which is AP1; the other is constitutively expressed, and its apparent concentration appears uninfluenced by banding. It is unclear what role either of these proteins may have in regulating ANF gene expression. Future experiments will be required to unravel the identity of the constitutively expressed factor and to characterize its functional role for the expression of the ANF gene in response to pressure overload.

\section{Acknowledgments}

The authors thank Dr. Christine Seidman for generously providing the -3400 ANF-CAT construct.

This study was supported in part by the National Institutes of Health (HL-38070 and HL-59417) and the Deutsche Forschungsgemeinschaft (Ha-1777/6-1).

\section{References}

1. Bloch, K.D., J.G. Seidman, J.D. Naftilan, J.T. Fallon, and C.E. Seidman. 1986. Neonatal atria and ventricles secrete atrial natriuretic factor via tissuespecific secretory pathways. Cell. 47:695-702.

2. Wu, J., C.F. Deschepper, and D.G. Gardner. 1988. Perinatal expression of the atrial natriuretic factor gene in rat cardiac tissue. Am. J. Physiol. 255: E388-E396.

3. Arai, H., K. Nakao, Y. Saito, N. Morii, A. Sugawara, T. Yamada, H. Itoh, S. Shiono, M. Mykoyama, H. Ohkubo, et al. 1988. Augmented expression of atrial natriuretic polypeptide gene in ventricles of spontaneously hypertensive rats (SHR) and SHR-stroke prone rats. Circ. Res. 62:926-935.

4. Lee, T.R., K.D. Bloch, J.M. Pfeffer, M.A. Pfeffer, E.J. Neer, and C.E. Seidman. 1988. Atrial natriuretic factor gene expression in ventricles of rats with spontaneous ventricular hypertrophy. J. Clin. Invest. 81:431-439.

5. Edwards, B.S., D.M. Ackermann, M.E. Lee, G.S. Reeder, L.E. Wold, and J.C. Burnett, Jr. 1988. Identification of atrial natriuretic factor within ventricular tissue in hamsters and humans with congestive heart failure. J. Clin. Invest. 81:82-93.

6. Drexler, H., J. Hänze, M. Finck, W. Lu, H.J. Just, and R.E. Lang. 1989. Atrial natriuretic peptide in a rat model of cardiac failure. Atrial and ventricular mRNA, atrial content, plasma levels, and effect of volume loading. Circulation. 79:620-633.

7. Knowlton, K., H. Rockman, M. Itani, A. Vovan, C. Seidman, and K. Chein. 1995. Divergent pathways mediate the induction of ANF transgenes in neonatal and hypertrophic ventricular myocardium. J. Clin. Invest. 96:13111318 .

8. Izumo, S., B. Nadal-Ginard, and V. Mahdavi. 1988. Protooncogene induction and reprogramming of cardiac gene expression produced by pressure overload. Proc. Natl. Acad. Sci. USA. 85:339-343.

9. Rascher, W., T. Tulassay, and R.E. Lang. 1985. Atrial natriuretic peptide in plasma of volume-overloaded children with chronic renal failure. Lancet. 2: 303-305.

10. Hasebe, N., L. Hittinger, S. Kohin, T.-Y. Shen, R.M. Graham, and S.F. Vatner. 1995. Effects of hypertrophy on left atrial and ventricular compliance and plasma ANF levels in conscious dogs. Am. J. Physiol. 268:H781-H787.

11. Matsubara, H., Y. Hirata, H. Yoshimi, S. Takata, Y. Takagi, Y. Umeda, Y. Yamane, and M. Inada. 1988. Role of calcium and protein kinase C in ANP secretion by rat cardiocytes. Am. J. Physiol. 255:H405-H409.

12. von Harsdorf, R., R.E. Lang, M. Fullerton, A.I. Smith, and E.A. Woodcock. 1988. Right atrial dilatation increases inositol-(1,4,5)trisphosphate accumulation. Implications for the control of atrial natriuretic peptide release. FEBS (Fed. Eur. Biochem. Soc.) Lett. 233:201-205.

13. von Harsdorf, R., R.E. Lang, M. Fullerton, and E.A. Woodcock. 1989. Myocardial stretch stimulates phosphatidylinositol turnover. Circ. Res. 65:494-501.

14. McBride, K., L. Robitaille, S. Tramblay, S. Argentin, and M. Nemer. 1993. fos/jun repression of cardiac-specific transcription in quiescent and growthstimulated myocytes is targeted at a tissue-specific cis element. Mol. Cell. Biol. 13:600-612.

15. Sadoshima, J., and S. Izumo. 1993. Molecular characterization of angiotensin II induced hypertrophy of cardiac myocytes and hyperplasia of cardiac fibroblasts. Circ. Res. 73:413-423.

16. Zhu, H., A. Garcia, R.S. Ross, S.M. Evans, and K.R. Chien. 1991. A conserved 28-bp-element (HF-1) in the rat cardiac myosin light-chain-2 gene confers cardiac-specific and alpha-adrenergic inducible expression in cultured neonatal rat myocardial cells. Mol. Cell. Biol. 1:2273-2281.

17. Simpson, P. 1983. Norepinephrine-stimulated hypertrophy of cultured rat myocardial cells is an alpha-adrenergic response. J. Clin. Invest. 72:732-738.

18. Kariya, K., I. Farrance, and P. Simpson. 1993. Transcriptional enhancer factor- 1 in cardiac myocytes interacts with an $\alpha_{1}$-adrenergic- and $\beta$-protein kinase $\mathrm{C}$-inducible element in the rat $\beta$-myosin heavy chain promoter. J. Biol. Chem. 268:26658-26662.

19. Kariya, K., L. Karns, and P. Simpson. 1994. An enhancer core element mediates stimulation of the rat $\beta$-myosin heavy chain promoter by an $\alpha_{1}$-adrenergic agonist and activated $\beta$-protein kinase $\mathrm{C}$ in hypertrophy of cardiac myocytes. J. Biol. Chem. 269: 3775-3782.

20. Rosenzweig, A., T.D. Halazonetis, J.G. Seidman, and C.E. Seidman. 1991. Proximal regulatory domains of rat atrial natriuretic factor gene. Circulation. 84:1256-1265.

21. Molkentin, J., and B. Markham. 1994. An M-CAT binding factor and an RSRF-related A-rich binding factor positively regulate expression of the $\alpha$-cardiac myosin heavy-chain gene in vivo. Mol. Cell. Biol. 14:5056-5065.

22. Aoyagi, T., and S. Izumo. 1993. Mapping of the pressure response element of the c-fos gene by direct DNA injection into beating hearts. J. Biol. Chem. 268:27176-27179.

23. Lin, H., M.S. Parmacek, G. Morle, S. Bolling, and J.M. Leiden. 1990. Expression of recombinant genes in myocardium in vivo after direct injection of DNA. Circulation. 82:2217-2221.

24. Kitsis, R.N., P.M. Buttrick, E.M. NcNally, M.L. Kaplan, and L.A. Leinwand. 1991. Hormonal modulation of a gene injected into rat heart in vivo. Proc. Natl. Acad. Sci. USA. 88:4138-4142.

25. Buttrick, P.M., A. Kass, R.N. Kitsis, M.L. Kaplan, and L.A. Leinwand. 1991. Behavior of genes directly injected into the rat heart in vivo. Circ. Res. 70: 193-198.

26. Acsadi, G., S. Jiao, J. Agnes, D. Duke, P. Williams, W. Chong, and J.A. Wolff. 1991. Direct gene transfer and expression into rat heart in vivo. New Biol. 3:71-81.

27. von Harsdorf, R., R.J. Schott, Y.-T. Shen, S.F. Vatner, V. Mahdavi, and B. Nadal-Ginard. 1993. Gene injection into canine myocardium as a useful model for studying gene expression in the heart of large mammals. Circ. Res. 72:688-695.

28. Gorman, C.M., L.F. Moffat, and B.H. Howard. 1982. Recombinant genomes which express chloramphenicol acetyltransferase in mammalian cells. Mol. Cell. Biol. 2:1044-1051.

29. DeWet, J.R., K.V. Wood, M. DeLuca, D.R. Helinski, and S. Subramani. 1987. Firefly luciferase gene: structure and expression in mammalian cells. Mol. Cell. Biol. 7:725-737.

30. Widom, R.L., J.A.A. Ladias, S. Kouidou, and S.K. Karathanasis. 1991. Synergistic interactions between transcription factors control expression of the apolipoprotein AI gene in liver cells. Mol. Cell. Biol. 11:677-687.

31. Seidman, C.E., D.W. Wong, J.A. Jarcho, K.D. Bloch, and J.G. Seidman 1988. Cis-acting sequences that modulate atrial natriuretic factor gene expression. Proc. Natl. Acad. Sci. USA. 85:4104-4108.

32. Grueneberg, D., S. Natesan, C. Alexandre, and M. Gilman. 1992. Human and Drosophila homeodomain proteins that enhance the DNA-binding activity of serum response factor. Science (Wash. DC). 257:1089-1095.

33. Seed, B., and J.Y. Sheen. 1988. A simple phase-extraction assay for 
chloramphenicol acetyl transferase activity. Gene (Amst.). 67:271-277.

34. Deryckere, F., and F. Gannon. 1994. A one-hour minipreparation technique for extraction of DNA-binding proteins from animal tissues. Biotechniques. 16:405

35. Argentin, S., A. Ardati, S. Tremblay, I. Libermann, L. Robitaille, J, Drovin, and M. Nemer. 1994. Developmental stage-specific regulation of atrial natriuretic factor gene transcription in cardiac cells. Mol. Cell. Biol. 14:777-790.

36. Rauscher, F.J., III, L.C. Sambucetti, T. Curran, R.J. Distel, and B.M. Speigelman. 1988. Common DNA binding site for Fos protein complexes and transcription factor AP-1. Cell. 52:471-480.

37. Nakabeppu, Y., K. Ryder, and D. Nathans. 1988. DNA binding activities of three murine jun proteins: stimulation by fos. Cell. 55:907-915.

38. Allegretto, E., T. Smeal, P. Agel, B.M. Speigelman, and K. Karin. 1990. DNA-binding activity of Jun is increased through its interaction with Fos. $J$. Cell. Biochem. 42:193-206.

39. Sprenkle, A., S. Murray, and C. Glembotski. 1995. Involvement of multiple cis elements in basal and $\alpha$-adrenergic agonist-inducible atrial natriuretic factor transcription. Circ. Res. 77:1060-1069.

40. Kovacic-Milivojevic, B., and D.G. Gardner. 1992. Divergent regulation of the human atrial natriuretic peptide gene by c-jun and c-fos. Mol. Cell. Biol. 12:292-301.

41. Sheng, M., S.T. Dougan, G. McFadden, and M. Greenberg. 1988. Calcium and growth factor pathways of c-fos transcriptional activation require distinct upstream regulatory sequences. Mol. Cell. Biol. 8:2787-2796.

42. Fisch, T.M., R. Prywes, M.C. Simon, and R.G. Roeder. 1989. Multiple sequence elements in the c-fos promoter mediate induction by cAMP. Genes Dev. 3:198-211.

43. Chiu, R., W. Boyle, J. Meek, T. Smeal, T. Hunter, and M. Karin. 1988. The c-fos protein interacts with c-Jun/AP1 to stimulate transcription of AP-1 responsive genes. Cell. 54:541-552.
44. Sheng, M., and M.E. Greenberg. 1990. The regulation and function of c-fos and other immediate early genes in the nervous system. Neuron. 4:477485 .

45. Okeefe, D., J. Hoffman, R. Cheitin, M. O'Neill, J. Allard, and E. Shapkin. 1978. Coronary blood flow in experimental canine left ventricular hypertrophy. Circ. Res. 43:43-51.

46. Knowlton, K.U., E. Barachini, R.S. Ross, A.N. Harris, S.A. Henderson, S.M. Evans, C.C. Glembotski, and K.R. Chien. 1991. Co-regulation of the atrial natriuretic factor and cardiac myosin light chain-2 genes during alpha-adrenergic stimulation of neonatal rat ventricular cells. J. Biol. Chem. 266:7759-7768.

47. Sadoshima, J., and S. Izumo. 1993. Mechanical stretch rapidly activates multiple signal transduction pathways in cardiac myocytes: potential involvement of an autocrine/paracrine mechanism. EMBO (Eur. Mol. Biol. Organ.) J. 12:1681-1692.

48. Roesler, W.J., G. R. Vandenbark, and R. Hanson. 1988. Cyclic AMP and the induction of eukaryotic gene transcription. J. Biol. Chem. 263:9063-9066.

49. Xenophontos, S.P., P.A. Watson, B.H.L. Chua, T. Haneda, and H.E. Morgan. 1989. Increased cyclic AMP content accelerates protein synthesis in rat heart. Circ. Res. 65:647-656.

50. Schiaffino, S., J. Samuel, D. Sasson, A. Lompre, I. Garner, F. Marotte, M. Buckingham, L. Rappaport, and K. Schwartz. 1989. Nonsynchronous accumulation of alpha skeletal muscle actin and beta myosin heavy chain mRNAs during early stages of pressure overload-induced cardiac hypertrophy demonstrated by in situ hybridization. Circ. Res. 64:937-948.

51. Busch, S., P. Sassone-Corsi. 1990. Fos, Jun, CREB basic-domain peptides have intrinsic DNA-binding activity enhanced by a novel stabilizing factor. Oncogene. 5:1549-1556.

52. Mantymaa, P., O. Vuolteenaho, M. Marttila, and H. Ruskoaho. 1993. Atrial stretch induces rapid increase in brain natriuretic peptide but not in atrial natriuretic peptide gene expression in vitro. Endocrinology. 133:1470-1473. 